International Journal of Agriculture, Environment and Bioresearch

Vol. 4, No. 06; 2019

ISSN: $2456-8643$

\title{
SEEDING MACHINE COULTER SELECTION FORSEEDING WHEAT SEEDS IN BETWEEN THE COTTON ROWS
}

\author{
T.S.Xudoyberdiev - D.T.S., Professor, B.R.Boltaboev - C.T.S., Associate Professor, \\ B.N.Tursunov - C.T.S., Associate Professor, V.A.Kalashnikov - Researcher \\ Andijan branch of the Tashkent State Agrarian University \\ http://doi.org/10.35410/IJAEB.2019.4487
}

\begin{abstract}
At the present time, remains a problem of the choice of the seeder coulters for seeding wheat seeds in between the cotton rows that fully meets the all the requirements and that have less traction resistance.

To solve this problem, the existing designs of seeding machine coulters for seeding seeds of vegetable and gourds, cotton and wheat were analyzed, as a result it was found that these parts are not suitable to seed in between the cotton rows.

The article presents the results of the design development - two types of coulters for seeding wheat seeds in between the rows of cotton - the streamlined coulter and the roller coulter, which are simple in design, have relatively less traction resistance and allow multi-row seeding of seeds.
\end{abstract}

Keywords: Between the cotton rows, wheat sown, seeder, support wheels, section, gradil, shovel, bunker, traction resistance, combined aggregate, bed, seed lead

\section{INTRODUCTION}

General information. The second seed of the Don Seed provides the twin twigs with the right reproduction technology, as they are tasked with drifting at the specified depths, destroying the seedlings, and destroying the seeds. Qualitative accomplishment of these works also leads to loss of productivity [1,2]. For this, there is no shortage of paperwork, and the businessman needs to be able to work with both.

The problem. The day-to-day rhythmic swing profiles provide a great deal of exposure to sowing, and the use of perimeters to increase the degree of use of the perimeter of the ridge.

Problem solving methods. For bunching, the second generation of small seeds and don seeds is analyzed by the design and operation of the twins. As a result of the analysis, the advantages and disadvantages of UARning are studied, and some issues related to the development of Uarning do not change or make some changes. If such measures cannot be used in the same way, the new designs will come up. 
Overview of crooked eclipse tours. Different types of ecliparing are different, and the main principles of ularing are shown in Figure 1 [3, 4].

According to the technological process, the two are: discus (Fig. 1a), auxiliary (Fig. 1b), syrup (Fig. 1b), ankle (Figure 1b), ankle (Figure 1b), right beak (1e). picture) is divided into tours.

It is not uncommon for the two of us to follow the design of the Yokori design, as they do so. With the exception of the $1 \mathrm{v}-2$ icon. This is because these two cotton seeds have been used almost unchanged.

$1 \mathrm{~d}, \mathrm{e}, \mathrm{d}-\mathrm{e}$ are deeper in the process, and $1 \mathrm{~b}, \mathrm{a}, \mathrm{c}$ - features the retrograde features.
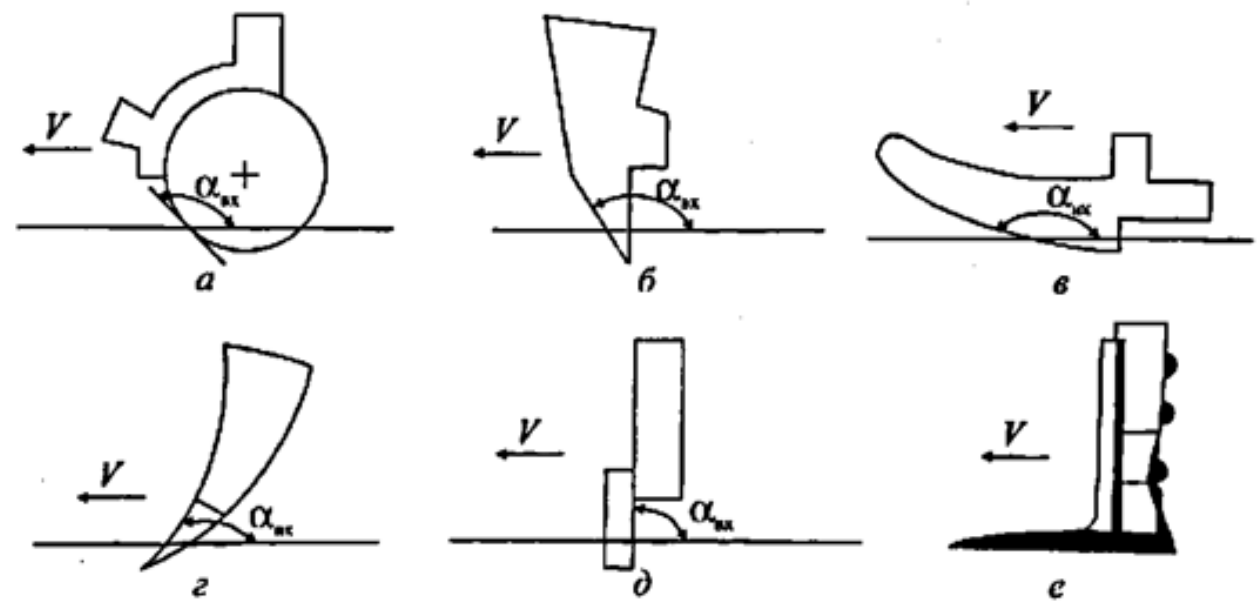

a-disc, b-auxiliary, c-syringe, d-anchor, d-force, e-uv-yi beak.

V-directional inclination, $\alpha$-problems angle.

Figure 1. Tours of bicycles.

At present, the design of different sizes and sizes of seedlings for vegetable and melon, cereals and cotton for seed cultivation has been taken into account.

Although the shape and dimensions of the twins are not exactly the same as those shown in Fig.

We limit ourselves to duplication, layout, detailing and mapping functions, but focus on the type of ecosystems, contours, and dimensions. Because, when used in cotton or used in combinations, the dimensions of two dimensions, namely, the design and dimensions, are of primary importance.

We analyze the design of ulcers in order to find out how many different seeds can be used in a wide range of different profiles, from existing and currently used twins. 
Second seed of small seeds. The second batch of small seed seeds is intended for sowing, mainly in the arid areas. The wardrobe has a variety of designs, and the seeds are mounted on a turban 8 ... $25 \mathrm{~cm}$ wide.

Figure 2 shows the ecosynthetic triple extinction of vegetable seeds CO-4,2. These two eclipses have one and two drops of discs that can work in different climatic conditions and up to 100 ha of fantasy. [5,6]
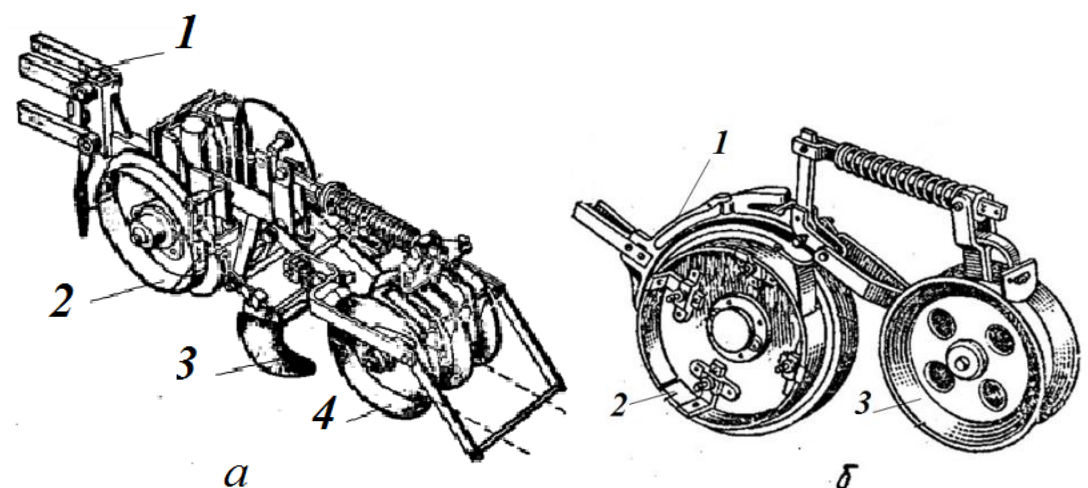

(a) Double row disc drives, frame 1, disc 2, 3rd generation hood, 4 cone roller.

b) a series of double disc drives, 1 case 2 disc, 3 cone roller.

Picture 2 Two-dimensional CO-4,2 triplicate.

The modifications of the SKON-4.2 ounce yн are identical to the two-dimensional design of the two - [7].

Yucoria (Figure 2) shows the possibility of using or reconfiguring the ruined ecclesiastical structures.
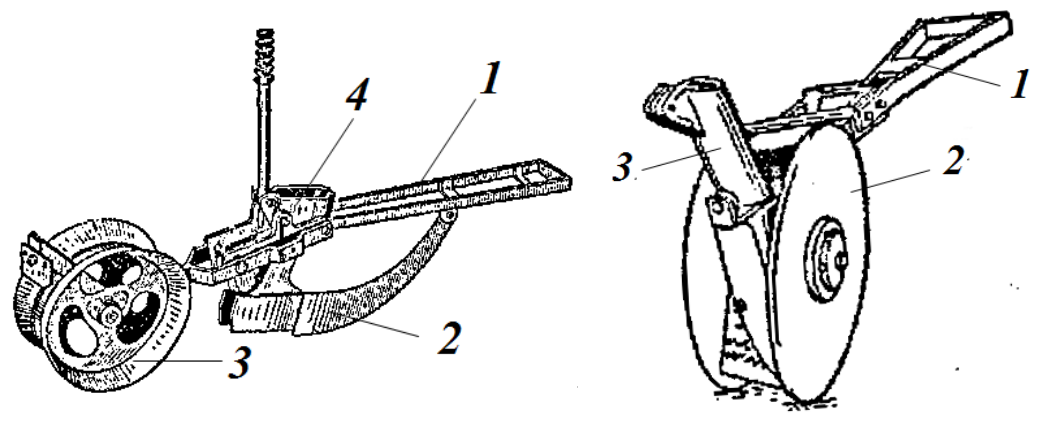

a-helmet eccentric, 1st cake, second auxiliary eccentric, 3rd conical zipper roller, 4-seed roller.

b-SUUP-48 re-engineered twin, 1-cake, 2-disc drive, 3-seed roller. 
Figure 3: The seedling and re-engineered seed, the tasaliekuccuchi ecch.

The duplication of the SON-2,8 A three-dimensional disks designed for planting seed and vegetable seedlings for seeding is shown in Figure $3[8,2]$.

These two are intended for planting small seeds. The re-use of a double disc is unlikely to be used as the twin discs of most of the seeds, which are in the free space, are considered double disks.

The Mayak Experimental Breeding Station is an eccentric eccentric design for $25 \mathrm{~cm}$ wide onion seed, and the four-seeded version of the four-seeded plant at the Kyrgyz Institute of Agricultural Research.

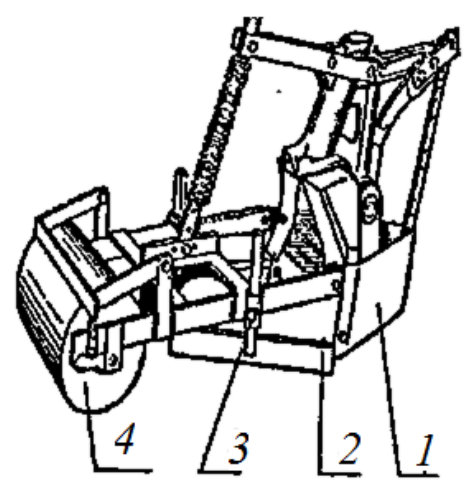

$a$

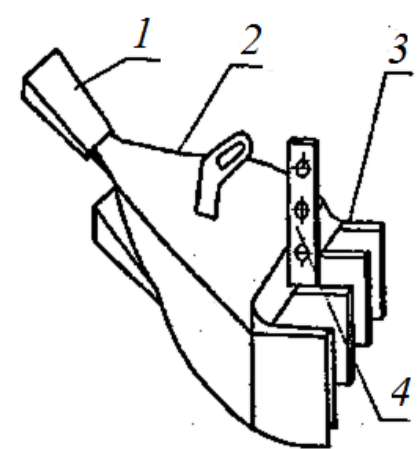

6

a- The design of the "Mayak" Experimental Station is a 1-wheeler, a 2-rod, a 3-seed separator, and a 4-zipper roller.

b-Kyrgyzstan Agricultural Research Institute Design. The 1st seed is the spearhead, the 2nd seed divider, the third auxiliary, the 4th seed deeper.

Fig. 4.

In addition to the wardrobe design, the inspiration for use is evident.

Filing for plowing, filing, forging, Moldova Agricultural Research Institute Two of them were also analyzed by the Department of Machines. [2,11,12].

As a result of the study of the designs of the second seed of small seeds, it was concluded that there is a potential for use in seeding or seed mating.

It is important that the plant should be able to provide the seeds of the seed, as well as the seeds of the seed. 
Analysis of second-order seed production in cotton plants. In many ways, the development of donning properties in a range of ways depends on the two. With the help of the two, planting the seeds to the same depth and squeezing the fields around the same distribution causes the harvesting to occur. [1,2]

Despite the fact, the use of kangaroos in seeding orchard cultivation has always been the norm $[21,4]$.

The seeds of the cotton seed can be paired with double or double ecclesiastics, which are relatively coarse in the series, and are traditionally used by the twins. These two are intended for a steep slope and do not achieve the same effect when used in a row. With the help of flies, the seed sprouting (6 rows) is formed by the irrigation canal. Such technology lowers the degree of perimeter utilization. In addition, a large number of chassis discs are added to the ULaring dimensions for a large number of installations. Soon, there was a slowdown in the number of meetings for such two.

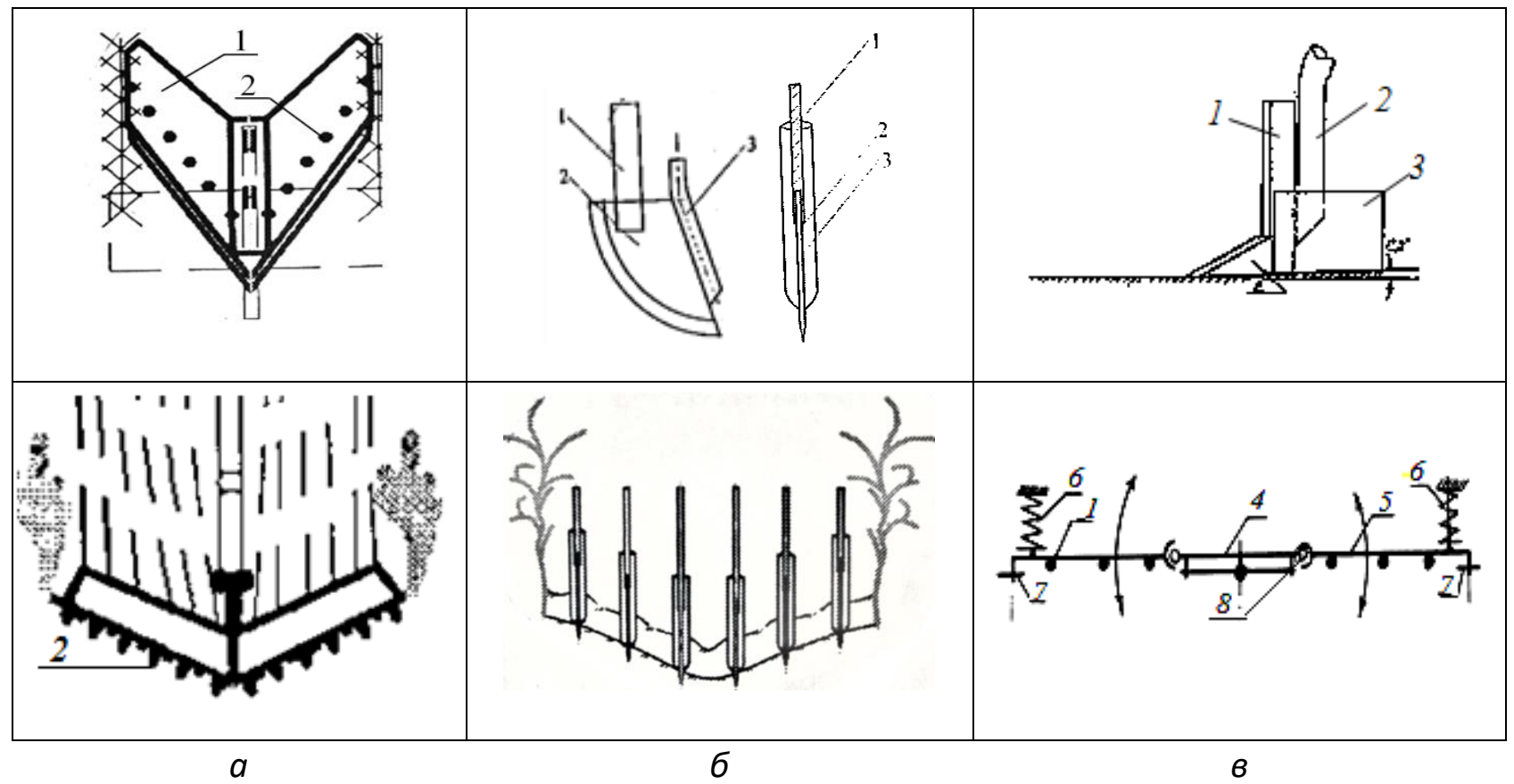

a- spider-glass. 1-wheeler, 2-eccentric.

b- my boyfriend is an eccentric knife. 1-second pole, 2-inch knife, 3rd seed

c- screwdriver. 1-second, 2-seeders, 3-planks, 4-ramming center section, 5-ramming wing, 6th springs, 7-second deep holes, slippers, 8-hinge.

Figure 5. Seeds of the Ecuadorian Hercules, the second seed of the orange. 
Under the guidance of Professor TS Khudoyberdiev many small numbers of minors have been proposed for the establishment of small quantities [13,14,15], (Fig. 5) and recommendations on their use $[16,17]$.

Sliding sowing. This is the basis of double-sourcing, namely, the form of sour cream as a form of profiling. Based on the schematic diagram, the twin is mounted with a cutting knife. Ecci's time is one of the seed sprints. It is based on the waning parameters [8]. Fig. 5a shows the slicing of serpents and cats. There are also some disadvantages with these twin pants, which means that after twinning, the change in sagging profits will not fit into the profile of the syrup. This time it affects the depth of the sowing on the part two.

Flat sowing. Each of the twin tweezers moves freely, and according to the specified scheme, a large number of seed germinates, Figure $5 \mathrm{~b}$. There are no cases of uterine weighing of the uterus, as the Ekkich "helmet" type and the rotating radius of the hinge are rotated. Alien worms are either lost or crushed in the low tide because of the fact that the knife-wielding corners are justified [19]. There is also a shortage. At the same time, the seed germinates with a time-lapse, that is, the destroyer. However, before the seed germinates, a well-known part of the seed will grow. This also causes the seed to slip into the ditches at a specified depth.

Hornblack double. This is an improved version of the two. It is equipped with knives for cutting and sliding wolves and forcing them to move down and down. [20]. After all, the two horns of the seed puppet are mounted on the trunks. When these planks are gone, they kill the seeds in the trunk. Figure $5 b$.

According to the scheme, which is set in a row with cotton, the second seed is transmitted to the common flock. The central part of the ramming is tilted and the wings are flipped and the flippers of the egatillary fade. The winged hinge is almost welded to the Ramaningermarket part, so that the depth of planting is evenly distributed when the illusion is transformed. The wings have been mounted in the nest to the eagle's wig. [22] There is a flaw in this one, and even in some points, because of the fact that the two anchors are broken, they straddle the strangers.

In a nutshell, it is possible to use the seed in the yacht for a number of seeds. However, in the case of further shortcomings, in some cases the seeds can be affected by sowing quality and cross-fertilization. This time it can be puzzled by a peculiar puzzle.

Seeds devastated by the two orthogonal plants that are free from the shortcomings of the second generation. Taking advantage of the fact that the Yugoslav ruins were used in the construction of the two excavations, defeating the two dislocations, which were free of defects, could work in all conditions, and the number of high perimeters would be high. The following are the most basic requirements for twins that meet these requirements:

1. Low odds of them compared to idols;

2. Strengthening the ability to work closely with the weeds and the leaves that have been erected in the row;

3. Under all conditions, the two are fully able to perform their duties; 
4. Separation of the intermediate profile profile.

The structures that meet these requirements have been demolished. The first of these is called "chilly" and the second is called "conditional".

Eclipse in the form of "magic" The design of the exchanger is simple;

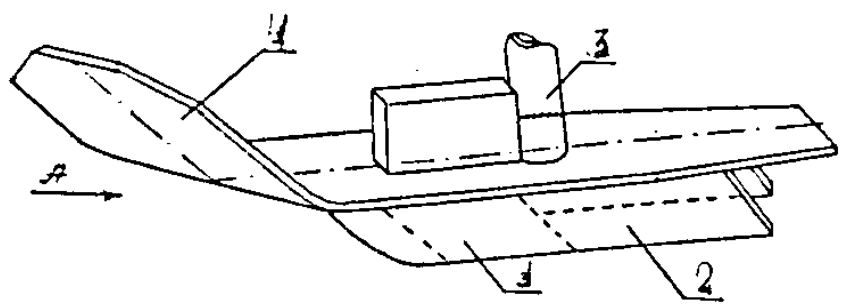

1-seeding knife, 2-seeded arachnichagus tufted seed plank, 3-seed sprayer, 4-inch deep cutter and sponge grill.

Picture 1 The structure of the eclipse in the "sauce" form.

The two parts are divided into two parts: the twin part 1, the Tuprokni Seed trimmer 2, the seeder 3 , and the outermost depth of the slider. Before you decide on the value of the corner, the ounce of the optimum value is clear. As the optimum cost is doubled, the ун rst will be назар nished according to theoretical research. The nuptial velocity of nose-tipping is observed in Vk (Figure 7b). Wning is based on the analytic method of solving the rules of expression [20] ie

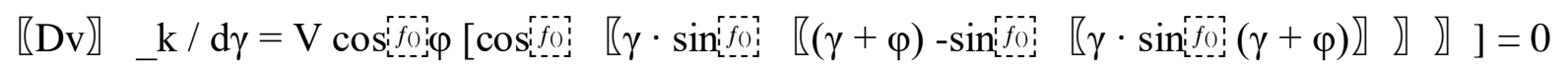

Here: $\mathrm{V}$ is the speed of aggregation, $\varphi$ is the angle of friction.

The sowing process is generally carried out at a speed of $2 \mathrm{~m} / \mathrm{s}$. Taking the friction angle $\varphi=$ $25^{\circ}$ and $\varphi=35^{\circ}$, we find that the optimum angular momentum of the initialization angle is $27 \ldots$ $33^{\circ}$ ha equation $[20]$.

It is necessary to divide the cutting edge or the ounce into the optical image of a small piece of gear. As a result of the movement, it is necessary to avoid the excavation of the yachting, which is infected by the excavation. It was agreed that a new two-quarter revision was made at $22 \ldots 25$ ha. After receiving such a condition, the seed springs up and drops the seeds.

The only disadvantage of sowing is that it has a lot of luck with the Jumper. This short sleeve can be straightened through the spring. In these two sets, we have the opportunity to look at the distribution of weeds. 
Double roller coil. The design of the roller exchanger is shown in Figure 7. The double echo of this design has been used in small bites such as the Sepadigan trilogy and the seed seed in the Ecuador.

Dual roller rollers are created: roller 1, roller caption2, twin 3, seed crusher 4, crusher slices 5 , roller sash 6.

The eccentric roller eccentric roller eccentric 1 twin drives the original, ie, the seed carrier is in the primary quality, and when it comes to the separation of the strings, the cut-offs are cut or down. This will simplify the work of duplication.
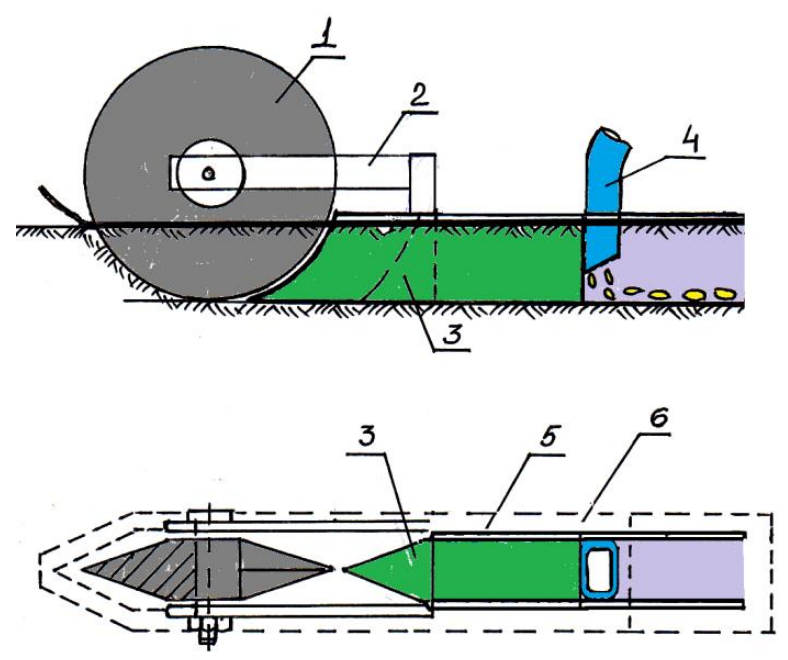

1 roller, 2 roller bearings, 3 double, 4 -seed rollers, 5-tube drill rods, 6-inch deep slipper spinner.

Figure 7. Double roller coil.

Rolling is a concussion, both anchorage, and the same angles of Uarning. Each horizontal piece of twitching is equal to $1 \ldots 1.5 \mathrm{~mm}$, with rolling ends with the ends of the rollers, reducing twitching. Here both small and roller rolling angles are always accepted as small, at the optimum cost.

\section{CONCLUSION}

It is clear from the analyzes that the larvae do not fit the size and size of the ularings for the use of the second pair of seeds.

2. Some of the flaws in the series of cranberries, slices, slices, and hinges, which are often used for seeding, require the choice of working conditions. This will slow down the business process.

3. It is advisable to use the "jigsaw puzzle" and roller coil for the purpose of leaving the gaps free. 
4. The selected scaling angle should be always smaller than the optimum value of the rotation angle, which is determined on the basis of the cross-section of the $\gamma$ ow, and the fact that the $y$ owning hole is not present.

\section{REFERENCES}

1. Zayats EV Bicycles. Hakimov R., Hakimov A., Askarov H. Onion pruning. - Minsk. YV. Minecraft! -2016. -106 hrs. And flour milling technology. - T .: Uzbekistan Research Institute of Vegetable and Vegetable Plants and Potato. 2005. -31 p.

2. Sochinev SI Development of constructive and cinematic parameters with the rotaryluminescent semiconductor semiconductor // Dissertation. Tech. Nauk. - Penza-2005-149c.

3. Shumarova M.Sh., Abdullaev TA Agricultural machines.-Tashkent: Kitsuitchi, 2002. - 424 p.

4. Mamatov FM Agricultural machines.- Tashkent: Fan, 2007. -339 p.

5. Ustinov AN Cars for cars and cellars. -M .: Agroprom - search.1989, -159p.

6. Hansky VM, Gorbachev IV machine-M: Kolos, 2004.-624c.

7. Nanaenko AK, Abramov AA, Loktionov GG, Orozoliev TA The kit is designed to work on the SKON-4,2.

8. Zagudaev SD Conversion of the semicircular lens and the application of the superimposed apparatus. -Penza: 2013-19s.

9. Kruchin NP Vehicles. Constructions and tendencies of development: - Samara: RHCSA. 2009. $-176 \mathrm{c}$.

10. Orozoliev TA, Nanaenko AK Mushroom culture of the // // Puppies. Kyrgyz Scientific Research Institute. —Frunze, 1977. —Wyp 14. —S 144 ... 146.

11. Chichkin VP Owls and combined combinations. - Chisinau: Štinka, 1984. -392 p.

12. Patent RF No. 2120722 Soshnik. Loryushin NP, Kopchinsky AA, Kukmazov KZ, Polikanov AV, Golivets VA B.I. -1998. -30.

13. Use of Medellum Ruz № FAP 00702. Ekcic. / Hudoyberdiev TS, Igamberdiev AK, Vakhobov AA Mirzakhmedov AT // Official Bulletin. -2012-№3.

14. Use of madelga Ruz № FAP 00721. A compound for planting cotton seeds. / Hudoyberdiev TS, Igamberdiev AK, Vakhobov AA Mirzakhmedov AT // Official Bulletin. -2012-№5.

15. Use of Madeleine Ruz \# FAP 00722. Syrpanma Ekki. / Hudoyberdiev TS, Igamberdiev AK, Vakhobov AA Mirzakhmedov AT // Official Bulletin. -2012-№5.

16. Hudoyberdiev TS, Igamberdiev AK, Mirzakhmedov AT Recommendations for the use of steam seedlings with two knife blades. - Tashkent: TIIM, 2011. -B 18. 
17. Khudoyberdiev TS, Igamberdiev AK, Vakhobov AA Recommendations for sowing with cotton sapanas and winter wheat. - Tashkent: TIIM, 2011. -B 24.

18. Igamberdiev AK Mainstreaming Parameters for the Fish Pumps in the Flat Pump // // AGROILM / -Tashkent. 2011 No. 3 - B 72-73. (05.00.00; No. 3).

19. Hudoyberdiev TS, Mirzaahmedov AT Substantiation of arc parameters - shaped furrowopener knife // European Science Review Austria, Vienna 2017. May-June No.56 B80-81.

20. Hudoyberdiev TS, Khudoyorov AN, Abdullaev DA The basic parameters of seeding and seeding are the following: // Irrigation and reclamation. - Tashkent. 2018- No. 4 (14). $52-57$ p.

21. Toshboltaev MT, Korakhonov A. Effective use of equipment in the autumn, the main method of the harvesting. // Uzbek Agricultural Journal. Tashkent 2010 No. 10-2-3p 